\title{
COMPLICATIONS OF PREGNANCY AMONG ADOLESCENTS AND ADULT MOTHERS TREATED IN A PUBLIC HOSPITAL, THE REPUBLIC OF LIBERIA: A RETROSPECTIVE COMPARATIVE STUDY
}

\author{
Alieu Sekou Konneh ${ }^{1}$ and Siti Khuzaimah Ahmad Sharoni ${ }^{1 *}$ \\ ${ }^{1}$ Centre for Nursing Studies, Faculty of Health Sciences, Universiti Teknologi MARA, Puncak Alam Campus, 42300 Puncak \\ Alam, Selangor, Malaysia.
}

*Corresponding author: Siti Khuzaimah Ahmad Sharoni

Email: sitik123@uitm.edu.my

\begin{abstract}
Complications of pregnancy remain a serious threat in Sub-Saharan Africa despite efforts to minimise maternal mortality due to pregnancy complications, and achieve the Millennium Development Goal 5. This is a retrospective study to determine the most common pregnancy complications among adolescents compared to adults treated in a public hospital from 2015 to 2018. The researcher applied a convenience sampling method in selecting the medical records. The instrument used was adapted from previous studies and data were analysed with descriptive and chisquare test for the inferential statistics. A total of 1,265 patients met the eligibility criteria and 540 (42.7\%) were adolescents. Low birth weight $(n=478,88.5 \%)$ and preterm delivery $(n=496,91.9 \%)$ were common among babies born to adolescent mothers. Pregnancy-related complications among adolescent mothers showing the prevalence of anaemia, hypertension, and malaria were 494 (84.9\%), 149 (56.2\%) and 193 (62.1\%) respectively. Gestational diabetes was found to be high among adult mothers ( $n=98,74.8 \%)$. Among adolescent mothers, the prevalence of eclampsia was 62 (78.5\%) and hemorrhage 61 (53.0\%). The prevalence of Intrauterine growth restriction (IUGR) was high among adolescent mothers $(n=252,80.5 \%)$. Comprehensive strategies are needed to keep girls in schools and to raise awareness and develop campaigns about using contraception properly to reduce the incidence of adolescent pregnancy as well as to minimise the incidence of pregnancy-related complications.
\end{abstract}

Keywords: Adolescent, Pregnancy, Complication.

\section{INTRODUCTION}

Adolescent pregnancy is a significant public health issue as it often occurs in conditions with poor social care and maternal well-being. It is a health problem associated with complications of childbirth due to growing emotional maturity as well as physical and physiological status 1. According to the United Nations International Children's Emergency Fund 2, adolescent pregnancy is a situation where girls who have not reached adulthood (between the ages of 13 - 19) become pregnant. Approximately 21 million girls aged 15 to 19 years, including 2 million girls below 15 years, give birth annually in developing countries ${ }^{3}$.

Adolescent pregnancy is generally associated with horrific outcomes for both the mother and child, and its effect plays a significant role in the lives of adolescents, their families and society in general. Adolescence is known to be a transition period from childhood to adulthood. This lifespan is related to the stages of changes essential to an adolescent girl's development and growth. The adverse effect of teenage pregnancy encompasses abandonment and low educational achievement, resulting in mediocre performance in the job market, leading to weak and inadequate nutrition, medical care for both the mother and the child, and poverty ${ }^{4}$.
The birth rate among adolescents in Sub-Saharan Africa remained the highest compared to developed countries. The birth rate among women ages 15 to 19 years in Sub-Saharan Africa reached over 200 births per 1000 girls ${ }^{5}$. Liberia is among the developing nations that has an alarming rate of adolescent pregnancy in the world, $38 \%{ }^{6}$. About 3 out of 10 Liberian girls got pregnant before turning 18 years old ${ }^{7}$.

Complications of pregnancy are health problems that occur during pregnancy and can involve either the mother's health, the baby's health, or both ${ }^{8}$. Complications of pregnancy among adolescent girls and childbirth are the leading causes of death among teenagers aged $15-19$ in low-and-middle-income countries, resulting in thousands of deaths each year 9. The most common pregnancy complications are hypertension, preeclampsia, eclampsia, premature labour, obstructed labour, cephalopelvic disproportion, miscarriage, low birth weight babies, gestational diabetes, ectopic pregnancy, and abruptio placenta ${ }^{10}$. A study conducted by Rudra, Bal, and Singh (2013) revealed that the complications amongst adolescents aged 16 - 19 years were maternal anaemia, hypertension disorders and preterm delivery. Ganchimeg et al. (2014) showed that preeclampsia, eclampsia, puerperal endometritis 
and systemic infections were higher amongst adolescent mothers than adult mothers. Cesarean section in adolescent mothers less than 15 years was $27.9 \%$ and $23.5 \%$ in the adult mothers.

According to Say et al. (2014), approximately 73\% of maternal mortality was caused by direct obstetric complications, whereas medical complications only accounted for $27.5 \%$ of all deaths of known causes. Among the immediate obstetric complications, hemorrhage was the leading cause of maternal mortality worldwide at $27.1 \%$ and hypertension disorder in pregnancy appeared second worldwide as the direct cause of maternal deaths ${ }^{13}$. According to the Liberian Demography and Health Survey $(2013)^{14}$, maternal mortality rate was 1,072 deaths per live births, many of which were associated with pregnancy complications and childbirth.

Liberia has a high maternal mortality rate, and many of the maternal deaths were pregnancyrelated complications ${ }^{15}$. The research will add to the body of knowledge about pregnancy complications among teenagers compared to nonteenagers in the hospital. It will help doctors and nurses in clinical decision making. The findings will also help nurses to either increase or maintain the current strategies to reduce adolescent pregnancy and identify pregnancy complications, especially those with high risks. Nurses can promote health awareness using the findings from this research to motivate adolescents to attend prenatal and antenatal clinics for early detection of any complications of pregnancy and thus either instigate the proper intervention or refer them to the appropriate institution for further management. The findings of this research can be forwarded to stakeholders to facilitate their decision-making and policy formulation regarding reducing maternal death rate incidence due to pregnancy complications among teens.

However, based on the numerous literature reviewed, it is vivid that there are minimum studies conducted on the complications of pregnancy amongst adolescents in the region of Nimba and Liberia as a whole. It is an indication of a significant knowledge gap. There is a need to conduct this study here in a government-owned regional referral hospital. This study's objective was to determine the most common pregnancy complications among adolescent mothers treated in a public hospital compared to adult mothers.

\section{METHODS}

A four-year retrospective, quantitative design study was conducted at the Jackson F. Doe Regional Referral Hospital Obstetrics and
Gynaecology Department from January 1, 2015 to December 31, 2018. Jackson F. Doe Hospital is a 100-bed tertiary care center receiving referrals from several health institutions within the Kparblee District and beyond. The hospital is located in the country's Central North region, South West of Nimba County to be precise, 216 kilometers away from Monrovia, the national capital city.

A convenience sampling technique was used to collect data. The process took two months after fulfilling all ethical requirements. A total number of 1,378 medical records of both adolescent mothers and adult mothers who attended the hospital during the study period were obtained. These medical records were thoroughly perused for eligibility. One thousand two hundred sixtyfive $(1,265)$ medical records met all eligibility criteria and were included in the study. The study compared pregnancy complications between teenage mothers and adult mothers.

\section{Inclusion and Exclusion Criteria}

The eligibility criteria were all adolescent mothers aged 11 years to 19 years and adult mothers aged 20 years and above. Mothers who had a pre-existing medical diagnosis before pregnancy were excluded. All incomplete medical records were excluded from the study.

\section{Instruments}

The research adapted the instruments used in Cameroon by Tamambang et al. (2018) and in Nigeria by Akadiri, Bakare, and Ajenifuja (2015) to conduct this study. The adapted instrument was subject to peer review by research experts who ensured that the tool was consistent while addressing ambiguities and concentrating on items that met the study's intended objective. The panel found that the instrument was appropriate for measuring the study material.

A total of 25 questions were used to review the medical records of both adolescent and adult mothers. The questionnaire covered the eligible participants' demographic data, clinical characteristics, mode of delivery, and pregnancy complications (medical, obstetrics, and fetal complications). The instrument was divided into four parts. Section A is demographics data with six items. Section B is clinical characteristics and fetal outcomes comprising of seven items. Section $C$ is the mode of delivery, and Section D includes medical complications, four items, obstetrics complications, five items, and fetal complications, two items.

\section{Ethical Consideration}

Ethical approval was obtained from the Research Ethics Committee of Universiti Teknologi MARA, Malaysia, Shah Alam Campus: Reference: 
REC/308/19, University of Liberia Pacific Research and Evaluation Institute (UL-PIRE IRB), reference: IOR0004203 and a letter of permission from Jackson F. Doe Memorial Regional Referral Hospital, reference JFD/ACEO/IAS/050-17.

\section{Data Analysis}

The data were analysed using descriptive methods (frequency and percentage, or mean and standard deviation). For inferential analysis, the Chisquare test was applied to analyse the categorical data. A p value of less than 0.05 was considered as statistically significant.

\section{RESULTS}

A total of 1,265 patients met the eligibility criteria and were included in the study. Most of the study participants were adults ( $n=725,57 \%)$, and $540(43 \%)$ were adolescents. The mean age of the adolescent mothers was 17 years $(S D=1.53)$, and adults was 30 years ( $S D=6.57)$. The highest educational level among adolescents was primary education ( $n=356,65.9 \%)$ and most adults completed secondary education ( $n=381,52.6 \%$ ). The proportion of adolescent mothers who delivered preterm and had a low birth weight baby were $496 \quad(91.9 \%)$ and 478 (88.5\%) respectively.

\section{Prevalence of Complications of Pregnancy among Adolescents Compared to Adults Medical Complications}

The result for anaemia showed a statistically significant association between anaemia among adolescents and that of adult mothers with $\chi^{2}$ (1) $=783.298, \mathrm{p}=0.001$. The prevalence of anaemia was higher among adolescents $(n=494,84.9 \%)$ compared to adult mothers $(n=88,15.1 \%)$. There was a statistically significant association between hypertension and the maternal age group $\left(\chi^{2}(1)\right.$ $=25.115, p=0.001)$. Adolescent mothers had an increased rate of hypertension during pregnancy $(\mathrm{n}=149,56.2 \%)$ compared to adult mothers $(\mathrm{n}=$ $116,43.8 \%)$. Malaria in pregnancy was $(n=193$, $62.1 \%)$ among adolescents and $(n=118,37.9 \%)$ among adult mothers. There was a statistically significant association between malaria in pregnancy among adolescents and adult mothers with $\chi^{2}(1)=63.244, p=0.001$. Meanwhile, the study found gestational diabetes to be higher among adult mothers $(\mathrm{n}=98,74.8 \%)$ than adolescents $(\mathrm{n}=33,25.2 \%)$. The result also revealed a statistically significant association between gestational diabetes and maternal ages where $\chi^{2}(1)=18.286, p=0.001$. See Table 1 .

\section{Obstetrics Complications}

Referring to Table1, the rate of eclampsia was prevalent among adolescents $(\mathrm{n}=62,78.5 \%)$ compared to adult mothers $(n=17,21.5 \%)$, and there was a statistically significant association between eclampsia among adolescents and adult mothers with $\chi^{2}(1)=44.125, p=0.001$. Hemorrhage was common among adolescents $(\mathrm{n}=$ $61,53.0 \%$ ) compared to adult mothers $(n=54$, $47.0 \%$ ). Hence, there was a statistically significant association between hemorrhage among adolescents and adult mothers as $\chi^{2}(1)=5.545$, $\mathrm{p}$-value $=0.019$. Meanwhile, there was no statistically significant association between age groups for preeclamsia, cephalopelvic disproportion and obstructed labour $(p>0.05)$.

\section{Fetal Complications}

The prevalence of intrauterine growth restriction (IUGR) was higher among adolescent mothers $(\mathrm{n}=$ $252,80.5 \%)$ compared to adult mothers $(n=61$, $19.5 \%$ ), and there was a statistically significant association between IUGR among adolescent mothers and adult mothers with $\chi^{2}(1)=243.203$, $\mathrm{p}=0.001$ (Table 1). On the other hand, intrauterine fetus death (IUFD) was higher among adult mothers $(\mathrm{n}=90,62.1 \%)$ compared to adolescents $(\mathrm{n}=55,37.9 \%)$, and showed no statistically significant association between them (Table 1).

\section{DISCUSSION}

The results showed that anaemia was prevalent among adolescent mothers, $85 \%$ compared to adult mothers $15 \%$. Banerjee et al. (2009), in a study conducted in Southeast Asia (India), found that anaemia among adolescent women was $63 \%$, which is lower than the rate of anaemia among adolescents in this current study. Several studies supported the view that teenage mothers have an increased risk of maternal anaemia compared to adult mothers 1718 19. In many cases, adolescent mothers who became pregnant out of wedlock tend to deny being pregnant and refuse to attend the prenatal clinic. As a result, they have limited experience regarding the process of pregnancy and may not be fully aware of an iron-rich diet that would reduce the risk of anaemia. In addition, malaria, which is an epidemic in the region, generally contributes to anaemia during pregnancy. Malaria, hookworm, other infectious diseases and inadequate nutritional intake had increased anaemic cases among pregnant women in the region, similar to the results of other studies conducted in other developing countries 2021 . If they had attended a prenatal visit, an iron supplement would have been given to all pregnant women at risk of anaemia, as instructed by the Ministry of Health Policy.

According to previous studies, anaemia in pregnancy was associated with a soaring risk of low birth weight among neonate and preterm delivery 22 , intrauterine growth restriction, and a low APGAR (a standard assessment for infants after delivery) score at 5 minutes 23 . In contrast, 
a study conducted in Tanzania by Stephen et al. (2018) found no association between anaemia and low birth weight and preterm delivery.

Malaria is an endemic disease in Sub-Saharan Africa. Okpere, Enabudoso, and Osemwenkha (2010) stated that according to the Ghanaian Ministry of Health, during pregnancy, malaria accounts for $28 \%$ of out-patient attendance, $14 \%$ of hospital admissions and $9 \%$ maternal death. The prevalence of malaria cases among adolescent mothers was $62 \%$ versus $38 \%$ among adult mothers. Malaria remains a significant health problem in Liberia for pregnant women due to the country's unsanitary and inappropriate waste management practices.

Table 1: Pregnancy-Related Complications

\begin{tabular}{|c|c|c|c|c|c|c|c|c|}
\hline \multirow[t]{2}{*}{ Variables } & \multicolumn{2}{|c|}{$\begin{array}{l}\text { Adolescent } \\
(n=540)\end{array}$} & \multicolumn{2}{|l|}{$\begin{array}{l}\text { Adult } \\
(\mathrm{n}=725)\end{array}$} & \multicolumn{2}{|l|}{$\begin{array}{l}\text { Total } \\
(\mathrm{N}=1265)\end{array}$} & \multirow[t]{2}{*}{$\begin{array}{l}\text { Test } \\
\text { Statistics }\end{array}$} & \multirow[t]{2}{*}{$p$-value } \\
\hline & $n=540$ & $42.69 \%$ & $n=725$ & $57.31 \%$ & $\mathrm{~N}=1265$ & $100 \%$ & & \\
\hline \multicolumn{9}{|l|}{$\begin{array}{l}\text { Medical } \\
\text { Complications }\end{array}$} \\
\hline Anaemia & & & & & & & 783.298 & $0.001^{*}$ \\
\hline Yes & 494 & 84.9 & 88 & 15.1 & 582 & 46.0 & & \\
\hline No & 46 & 6.7 & 637 & 93.3 & 683 & 54.0 & & \\
\hline Hypertension & & & & & & & 25.115 & $0.001^{*}$ \\
\hline Yes & 149 & 56.2 & 116 & 43.8 & 265 & 21.0 & & \\
\hline No & 391 & 39.1 & 609 & 60.9 & 1000 & 79.0 & & \\
\hline Malaria & & & & & & & 63.244 & $0.001^{*}$ \\
\hline Yes & 193 & 62.1 & 118 & 37.9 & 311 & 24.6 & & \\
\hline No & 347 & 36.4 & 607 & 63.6 & 954 & 75.4 & & \\
\hline Diabetes & & & & & & & 18.286 & $0.001^{*}$ \\
\hline Yes & 33 & 25.2 & 98 & 74.8 & 131 & 10.3 & & \\
\hline No & 507 & 44.7 & 627 & 55.3 & 1134 & 89.7 & & \\
\hline \multicolumn{9}{|l|}{$\begin{array}{l}\text { Obstetrics } \\
\text { Complications }\end{array}$} \\
\hline Preeclampsia & & & & & & & 0.271 & 0.603 \\
\hline Yes & 28 & 45.9 & 33 & 54.1 & 61 & 4.8 & & \\
\hline No & 512 & 42.5 & 692 & 57.5 & 1204 & 95.2 & & \\
\hline Eclampsia & & & & & & & 44.125 & $0.001^{*}$ \\
\hline Yes & 62 & 78.5 & 17 & 21.5 & 79 & 6.2 & & \\
\hline No & 478 & 40.3 & 708 & 59.7 & 1186 & 93.8 & & \\
\hline CPD & & & & & & & 1.667 & 0.197 \\
\hline Yes & 113 & 39.4 & 174 & 60.6 & 287 & 22.7 & & \\
\hline No & 427 & 43.7 & 551 & 56.3 & 978 & 77.3 & & \\
\hline Hemorrhage & & & & & & & 5.545 & $0.019^{*}$ \\
\hline Yes & 61 & 53.0 & 54 & 47.0 & 115 & 9.1 & & \\
\hline No & 479 & 41.7 & 671 & 58.3 & 1150 & 90.9 & & \\
\hline Obstructed Labour & & & & & & & 3.853 & 0.050 \\
\hline Yes & 38 & 33.9 & 74 & 66.1 & 112 & 8.8 & & \\
\hline No & 502 & 43.5 & 651 & 56.5 & 1153 & 91.2 & & \\
\hline $\begin{array}{l}\text { Fetal } \\
\text { Complications }\end{array}$ & & & & & & & & \\
\hline IUGR & & & & & & & 243.203 & $0.001^{*}$ \\
\hline Yes & 252 & 80.5 & 61 & 19.5 & 313 & 24.7 & & \\
\hline No & 288 & 30.3 & 664 & 96.7 & 952 & 75.3 & & \\
\hline IUFD & & & & & & & 1.515 & 0.218 \\
\hline Yes & 55 & 37.9 & 90 & 62.1 & 145 & 11.5 & & \\
\hline No & 485 & 43.3 & 635 & 56.7 & 1120 & 88.5 & & \\
\hline
\end{tabular}

Note: $C P D=$ Cephalopelvic Disproportion, IUGR=Intrauterine Fetus Growth Restriction, IUFD=Intrauterine Fetus Death; The Chi-square test was used to compare the proportion of the two groups for categorical data; $p<0.05$ was statistically significant

Malaria in pregnancy causes anaemia, abortion, and bleeding. The intermittent preventive treatment in pregnancy (IPTp) is sulfadoxinepyrimethamine (Fansidar) administered during the $2^{\text {nd }}$ trimester of pregnancy in all prenatal clinics in the country to protect pregnant women against malaria. IPTp reduces maternal malarial episodes, maternal and fetal anaemia, placental parasitemia, low birth weight, and neonatal mortality. Mosquito nets treated with insecticides were distributed to all pregnant women attending prenatal hospitals. These initiatives were national measures to avoid malaria and its complications during pregnancy. Teenage mothers may not have 
access to these preventive steps possibly due to denial, fear of parental pressure and health facilities' inaccessibility.

Gestational diabetes in this study was higher among adult mothers, $75 \%$ versus $25 \%$ among adolescent mothers. This study indicated that advanced maternal age was associated with gestational diabetes, which is similar to the findings of a study conducted in Cameroon by Egbe et al. in 2018. Maternal overweight and advanced age are associated with gestational diabetes. Women who are obese already have resistance to insulin before they got pregnant. The combined effects of rising resistance to insulin and reduced pancreatic islet function in aging placed older women at high risk of developing gestational diabetes. Women with a family history of diabetes also experience gestational diabetes.

In this study, hypertension during pregnancy was found to be higher among adolescent mothers than adult mothers. The prevalence of hypertension in pregnancy among adolescents and adult mothers were $56 \%$ and $44 \%$, respectively. Goonewardene and Waduge (2010) conducted a similar study among adolescents aged $13-16$ years, and the results for the proportion of gestational hypertension was lower (12\%) compared to our study. In contrast, Berhe et al. (2018) and Paladugu et al., (2018) found gestational hypertension to be more common among adult mothers age 35 and above. Pregnancy hypertension can be caused by smoking, alcohol, hypertension, family history, first-time pregnancy, and for those over 35 years of age. Most teens were nulliparous mothers, and they might engage in alcohol intake due to tension or other social issues.

If gestational hypertension is left untreated, preeclampsia will then ensue. Also, mothers with gestational hypertension are at risk of experiencing seizures during pregnancy. However, it is conspicuous that a majority of women in our study reported that they did not experience preeclampsia symptoms. It is suggested that early and frequent visits to a prenatal clinic can help assess elevated blood pressure during pregnancy and detect any sign and symptom of preeclampsia. Prenatal treatment will decrease the patient's risk of seizures or eclampsia.

The incidence of hemorrhage among adolescent mothers (53\%) was relatively higher than adult mothers (47\%), and the difference was statistically significant. Similarly, a study conducted in the USA by Kawakita et al. (2016) showed that adolescents had a statistically significant increased risk of hemorrhage during pregnancy. Although there are natural causes of haemorrhage during pregnancy, in this region, local herbs are widely used for treating diseases and conditions related to pregnancy, such as fever, vomiting, malaria and weakness. These herbs are not without any adverse effects during pregnancy which may lead to hemorrhage.

Intrauterine fetus growth restriction (IUGR) was statistically significant with higher prevalence among adolescents at $80.5 \%$ and only $19.5 \%$ among adult mothers. In contrast, another study found that maternal age below 16 years and above 35 years were associated with IUGR ${ }^{31}$. Also, it was reported that the rate of anaemia among adolescent mothers was one of the reasons for intrauterine growth restriction ${ }^{23}$, other than low nutritional status and lack of antenatal visit.

\section{CONCLUSION}

Adolescent pregnancy is both a public health concern and medical problem associated with an increased risk of pregnancy complications. The most prevalent complication of pregnancy among teenagers was anaemia. Other primary maternal complications found were hypertension, malaria, hemorrhage, and eclampsia, whereas neonatal complications comprised of low birth weight and preterm baby and intrauterine fetus restriction. However, gestational diabetes was found to be higher among adult mothers.

Healthcare professionals need to recognise that adolescent pregnancy is considered high risk, therefore pregnant adolescents need to be informed on the early reservation and routine antenatal attendance to help identify and manage any complications. An adolescent should have access to comprehensive reproductive health information and services that are evidence-based, confidential, developmentally appropriate, and culturally sensitive to mitigate these factors.

\section{Limitations}

This study was based on secondary data collected from medical records available for review, many of which could not be included in the study due to poor record-keeping processes. The data might be biased as most patients attending this hospital were from rural areas and a majority are Christians. Meanwhile, the rate of patients who were admitted to Jackson F. Doe Hospital might be lower, due to terrible road conditions compared to urban hospitals where patients' intake is never interrupted by road network. The sampling method and retrospective nature of this study also have a risk of selection bias.

\section{Acknowledgment}

We would like to extend our appreciation to the Islamic Development Bank for the financial support, the Research Ethic Committee of Universiti Teknologi MARA and Jackson F. Doe Hospital, as well as the Centre for Nursing Studies, 
Faculty of Health Sciences, Universiti Teknologi MARA, Malaysia.

\section{Conflict of interest}

The authors declare no potential conflict of interest.

\section{REFERENCES}

1. Leppert PC, The effect of pregnancy on adolescent growth and development. In Health and the Female Adolescent, 2014.

2. Htut SM, Prevalence, socio-demographic characteristic and associated medical factors of teenage pregnancy in selected maternal and child health clinics in kuching, 2010.

3. World Health Organization, Adolescent pregnancy fact sheet. Adolesc. Pregnancy Fact Sheet 2012;1-4.

4. Dopkins Broecker J, Hillard P, Pregnancy in Adolescence, Glob. Libr. women's med, 2009.

5. World Health Organization, Adolescent pregnancy - Unmet needs and undone deeds WHO Library Cataloguing-inPublication Data, 2007.

6. Kumar N, Global Facts about Wed and Unwed Adolescent Pregnancies and Their Psychosocial Effects: A Review of Literature. Obstet. Gynecol. Int. J, 2017(5);1-7.

7. Rehman G, Young, Female and Pregnant in Liberia, 2010.

8. Rodrigues PB, Zambaldi CF, Cantilino A, Sougey EB, Particularidades da gravidez de alto risco como fatores para o desenvolvimento de sofrimento mental. Trends Psychiatry Psychother, 2016(38);136-140.

9. Neal S, Matthews Z, Frost M, Fogstad H, Camacho AV, Laski L, Childbearing in adolescents aged $12-15$ years in low resource countries: A neglected issue. New estimates from demographic and household surveys in 42 countries. Acta Obstet. Gynecol. Scand. 2012(91);11141118.

10. Bale JR, Stoll BJ, Lucas AO, Improving Birth Outcomes: Meeting the Challenge in the Developing World, 2003.

11. Rudra $\mathrm{S}$, Bal $\mathrm{H}$, Singh $\mathrm{S}$, A retrospective study of teenage pregnancy in a tertiary care hospital. Int. J. Reprod. Contraception, Obstet. Gynecol. 2013(2);383-387.

12. Ganchimeg $\mathrm{T}$, Ota E, Morisaki N, Laopaiboon M, Lumbiganon P, Zhang J, Yamdamsuren B, Temmerman M, Say L, Tunçalp Ö, Pregnancy and childbirth outcomes among adolescent mothers: a World Health Organization multicountry study. BJOG, 2014(121);40-48.

13. Say L, Chou D, Gemmill A, Tunçalp Ö, Moller AB, Daniels J, Gülmezoglu AM, Temmerman M, Alkema L, Global causes of maternal death: a WHO systematic analysis. Lancet. Glob. Heal. 2014(2);e323-33.

14. The Liberia Demography and Health Survey, Liberia, 2013. https: / /dhsprogram.com/pubs/pdf/FR29 1/FR291.pdf.

15. World Bank Group, Trends in Maternal Mortality : 1990 to 2015. 2015 https: / /openknowledge.worldbank.org/b itstream/handle/10986/23550/report.pd $\mathrm{f}$; sequence $=1$.

16. Tamambang RF, Njim $T$, Njie $A E$, Mbuagbaw L, Mafuta A, Tchana $M$, Choukem SP, Adolescent deliveries in urban Cameroon: A retrospective analysis of the prevalence, 6-year trend and adverse outcomes. BMC Res. Notes, 2018(11);1-5.

17. Akadiri O, Bakare B, Ajenifuja K, Obstetric Outcome in Teenage Pregnancy in a Free Antenatal Care Setting in Southwest Nigeria. Nepal J. Obstet. Gynaecol. 2015(10);81-84.

18. Socolov D, lorga M, Carauleanu A, Ilea C, Blidaru I, Boiculese L, Socolov R, Pregnancy during Adolescence and Associated Risks: An 8-Year HospitalBased Cohort Study (2007 - 2014) in Romania, the Country with the Highest Rate of Teenage Pregnancy in Europe, 2017.

19. Rexhepi M, Hospital-Based Study of Maternal, Perinatal and Neonatal Outcomes in Adolescent Pregnancy Compared to Adult Women Pregnancy, 2019(7);760-766.

20. Msuya SE, Hussein TH, Uriyo J, Sam NE, Stray-Pedersen B, Anaemia among pregnant women in northern Tanzania: Prevalence, risk factors and effect on 
perinatal outcomes. Tanzan. J. Health Res. 2011(13);40-49.

21. Ononge $\mathrm{S}$, Campbell $\mathrm{O}$, Mirembe $\mathrm{F}$, Haemoglobin status and predictors of anaemia among pregnant women in Mpigi, Uganda. BMC Res. Notes, 2014.

22. Black RE, Victora CG, Walker SP, Bhutta ZA, Christian P, De OM, Ezzati M, Grantham-McGregor S, Katz J, Martorell $\mathrm{R}$, Maternal and child undernutrition and overweight in low-income and middleincome countries. [Review][Erratum appears in Lancet, 2013;382-396.

23. Kidanto HL, Mogren I, Lindmark G, Massawe SN, Nystrom L, Risks for preterm delivery and low birth weight are independently increased by severity of maternal anaemia. South African Med. J, 2013.

24. Stephen G, Mgongo M, Hussein Hashim T, Katanga J, Stray-Pedersen B, Msuya SE, Anaemia in Pregnancy: Prevalence, Risk Factors, and Adverse Perinatal Outcomes in Northern Tanzania. Anemia, 2018.

25. Okpere EE, Enabudoso EJ, Osemwenkha AP, Malaria in Pregnancy Training: Manual for Health Providers, 2010(51);109-113.

26. Egbe TO, Tsaku ES, Tchounzou R, Ngowe $M N$, Prevalence and risk factors of gestational diabetes mellitus in a population of pregnant women attending three health facilities in Limbe, Cameroon: A cross-sectional study. Pan Afr. Med. J. 2018(31);1-13.

27. Goonewardene I, Waduge RD, Adverse effects of teenage pregnancy. Ceylon Med. J. 2010(50);116.

28. Berhe AK, Kassa GM, Fekadu, GA, Muche AA, Prevalence of hypertensive disorders of pregnancy in Ethiopia: A systemic review and meta-analysis. BMC Pregnancy Childbirth 2018(18).

29. Paladugu RK, Donipudi PC, Chimata D, Jasti $M$, Adolescent pregnancy and its outcomes: a cross-sectional study. Int. J. Community Med. Public Heal. 2018(5);4408.

30. Kawakita T, Wilson K, Grantz KL, Landy HJ, Huang CC, Gomez-Lobo V, Adverse Maternal and Neonatal Outcomes in Adolescent Pregnancy. J. Pediatr. Adolesc. Gynecol. 2016(29);130-136.

31. Sharma D, Shastri S, Sharma P, Intrauterine Growth Restriction: Antenatal and Postnatal Aspects, 2016;6783. 